\title{
ANALISIS POLA HUJAN UNTUK MITIGASI ALIRAN LAHAR HUJAN GUNUNGAPI
} SINABUNG

\section{Analysis of Rainfall Pattern for Lahar Mitigation at Sinabung Volcano}

\author{
Supriyati ${ }^{1) *}$, Boedi Tjahjono2) dan Sobri Effendy ${ }^{2)}$ \\ 1) Program Studi Mitigasi Bencana Kerusakan Lahan, Sekolah Pascasarjana, Institut Pertanian Bogor, Kampus IPB \\ Dramaga, Bogor 16680 \\ 2) Departemen Ilmu Tanah dan Sumberdaya Lahan, Fakultas Pertanian, Institut Pertanian Bogor, Jl. Meranti \\ Kampus IPB Dramaga, Bogor 16680 \\ 3) Departemen Geofisika dan Meteorologi, Fakultas MIPA, Jl. Meranti Kampus IPB Darmaga Bogor 16680
}

\begin{abstract}
Lahar is a natural process that becomes a hazard when it affects people and the environment. Lahars that are formed by a high intensity of rain and then form flows are secondary volcanic hazards. Sinabung Volcano that erupted in 2010 to date has released pyroclastic materials more than a hundred million cubics that can become lahars. To anticipate lahars, it is necessary to find out the rainfall pattern around the volcano. Therefore, this rainfall pattern information can be used to prepare the mitigation plan in order to anticipate lahars at Sinabung Volcano. Analysis of rainfall pattern uses measurement data of Sampali Climatology Station, Parapat Geophysical Station and Tuntungan Geophysical Station from 2000 to 2017. Buishand Range is used to testing the homogeneity of rainfall records. Then, the distribution of rainfall is displayed in the bar chart. Trend analysis uses Mann Kendall Test. The result of this research shows that the rainfall pattern at Sinabung Volcano is an equatorial rainfall pattern with the highest rainfall in May and October. Besides, trend analysis also shows the increase of rainfall in May so that mitigation needs to be prepared well to anticipate the risk of lahar hazards.
\end{abstract}

Keywords: Buishand Range, equatorial, Mann-Kendall Test

\section{ABSTRAK}

Lahar merupakan proses alami, namun menjadi berbahaya jika memberikan dampak bagi manusia dan lingkungan. Lahar yang terjadi karena hujan dengan intensitas tinggi dan membentuk aliran merupakan bahaya sekunder gunung api. Gunungapi Sinabung yang meletus pada tahun 2010 hingga saat ini telah mengeluarkan material piroklastik lebih dari seratus juta kubik yang siap menjadi aliran lahar. Untuk mengantisipasi aliran lahar, perlu diketahui pola hujan di sekitar Gunungapi Sinabung. Informasi pola hujan dapat digunakan untuk menyusun rencana mitigasi menghadapi aliran lahar Gunungapi Sinabung. Analisis pola hujan menggunakan data hasil pengukuran Stasiun Klimatologi Sampali, Stasiun Geofisika Parapat dan Stasiun Geofisika Tuntungan dari tahun 2000 sampai dengan tahun 2017. Data curah hujan diuji dengan Rentang Buishand untuk mengetahui homogenitasnya, kemudian distribusi curah hujan ditampilkan dalam diagram batang. Analisis trend menggunakan regresi linier sederhana dengan waktu sebagai peubah bebas dan curah hujan sebagai peubah tak bebas. Hasil penelitian menunjukkan bahwa pola hujan di Gunungapi Sinabung merupakan pola hujan equatorial dengan dua puncak musim hujan pada bulan Mei dan Oktober. Analisis trend kenaikan curah hujan yang cukup tinggi juga terjadi pada bulan Mei, sehingga upaya mitigasi menghadapi aliran lahar perlu ditingkatkan pada bulan Mei dan Oktober.

Kata kunci: Rentang Buishand, equatorial, Uji Mann-Kendall

\section{PENDAHULUAN}

Lahar adalah sebuah istilah dari bahasa Indonesia untuk aliran debris dengan volume besar yang berasal dari lereng-lereng gunung berapi, terutama mengandung air, lumpur, dan debris batuan serta memiliki kepadatan yang dapat dibandingkan dengan cairan bahan beton (Schilling, 2014). Bahaya lahar terjadi ketika air permukaan memobilisasi material sisa erupsi gunung api berupa abu vulkanik, batu, pasir, dan kerikil, serta puing-puing vulkanik lainnya melalui lembah sungai dengan volume yang besar (Vallance et al., 2014). Lahar meluncur di lereng-lereng curam gunung berapi ke dalam dan di sepanjang saluran sungai sebagaimana aliran yang terdorong oleh gaya gravitasi hingga kecepatan $65 \mathrm{~km}$ $\mathrm{jam}^{-1}$. Ketika lahar meluncur ke hilir, partikel-partikel terbesar dalam aliran cenderung bermigrasi ke depan dan ke bagian lereng dimana secara langsung dapat mengikis atau merusak apapun pada jalur tersebut dan ketika aliran lahar berhenti maka bangunan dan daratan bisa terkubur oleh lapisan debris batuan dan lumpur (Schilling, 2014).

Aliran lahar dapat terjadi saat gunung api meletus atau jauh setelahnya, karena deposit piroklastik yang tersebar di sekitar gunung api setelah erupsi merupakan material yang siap menjadi aliran apabila terkena hujan. Lahar hujan merupakan bahaya sekunder dari peristiwa erupsi gunung berapi yang terjadi ketika turun curah hujan dengan intensitas tinggi sehingga bercampur dengan material lepas gunung berapi dan membentuk aliran (Hidayat et al., 2013). Aliran lahar yang berupa lumpur sangat pekat dapat mengangkut material-material berbagai ukuran, sehingga lahar dapat merusak daerah dilaluinya 
dan infrastruktur yang dilewatinya. Lahar merupakan proses alami yang menjadi bahaya jika berefek pada manusia dan harta benda (Schilling, 2014).

Pada saat Gunungapi Sinabung di Kabupaten Karo Provinsi Sumatera Utara meletus, banyak material vulkanik yang dimuntahkan dan tersebar ke beberapa daerah sekitarnya dalam radius terjauh $6 \mathrm{~km}$ dari pusat letusan (Saragih et al., 2015). Volume deposit material piroklastik yang berada di tenggara-timur Gunungapi Sinabung pada tahun 2015 mencapai $\sim 1,9$ x $108 \mathrm{~m}^{3}$ (Yulianto et al., 2016).

Di sisi lain, curah hujan di Kabupaten Karo tergolong cukup tinggi seperti yang tercatat pada tahun 2014 dimana curah hujan tertinggi (pada bulan April) sebesar 348 mm (BPS, 2015). Dengan banyaknya material gunung api dan tingginya curah hujan maka kemungkinan terjadinya aliran lahar semakin besar. Untuk mengantisipasi hal tersebut, Badan Geologi memberikan rekomendasi agar masyarakat yang berada dan bermukim di dekat sungai-sungai yang berhulu di Gunungapi Sinabung tetap waspada terhadap bahaya aliran lahar (Badan Geologi, 2017), terutama di saat musim penghujan. Hal ini karena sifat destruktif alami lahar berasal dari kecepatan, jangkauan, komposisi dan kesulitan dalam memprediksi kemungkinan terjadinya jika tanpa ada peringatan (Pierson et al., 2014).

Untuk memperkirakan terjadinya aliran lahar, faktor yang dapat diperhitungkan adalah kejadian curah hujan tinggi di wilayah deposit piroklastik. Untuk mengetahuinya maka perlu diketahui pola hujan dan trend yang terjadi. Indonesia terbagi menjadi 3 pola iklim utama yaitu Curah Hujan Pola Monsunal, Curah Hujan Pola Ekuatorial dan Curah Hujan Pola Lokal, disajikan dalam Gambar 1 (Aldrian et al., 2003).

Pola monsun dicirikan oleh tipe curah hujan yang bersifat unimodial (satu puncak musim hujan) dimana pada bulan Juni, Juli dan Agustus terjadi musim kering, sedangkan untuk bulan Desember, Januari dan Februari merupakan bulan basah. Sedangkan enam bulan sisanya merupakan periode peralihan atau pancaroba (tiga bulan peralihan musim kemarau ke musim hujan dan tiga bulan peralihan musim hujan ke musim kemarau) ditunjukkan pada Gambar 2. Daerah yang didominasi oleh pola monsun ini berada didaerah Sumatra bagian Selatan, Kalimantan Tengah dan Selatan, Jawa, Bali, Nusa Tenggara dan sebagian Papua (Hermawan, 2010). Pola ekuatorial dicirikan oleh tipe curah hujan dengan bentuk bimodial (dua puncak hujan) yang biasanya terjadi sekitar bulan Maret dan Oktober atau pada saat terjadi ekinoks disajikan pada Gambar 3, meliputi pulau Sumatra bagian tengah dan Utara serta pulau Kalimantan bagian Utara (Hermawan, 2010). Gambar 4 menunjukkan pola lokal unimodial yang dicirikan oleh bentuk pola hujan yang berlawanan dengan tipe hujan monsun, daerahnya hanya meliputi daerah Maluku, Sulawesi dan sebagian Papua (Hermawan, 2010).

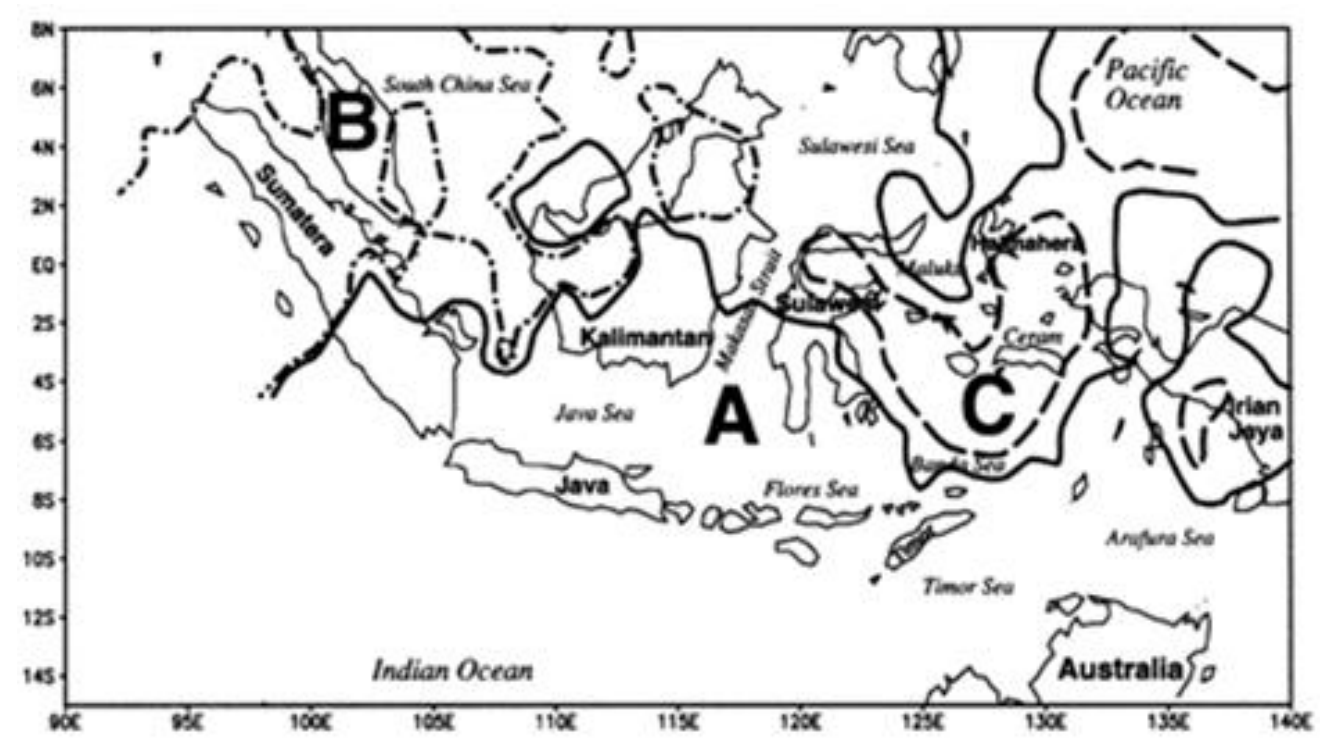

Gambar 1. Tiga wilayah iklim Indonesia. Wilayah A (monsun) garis hitam, Wilayah B (ekuatorial) garis dan titik, Wilayah C (lokal) garis putus-putus (Aldrian et al., 2003) 


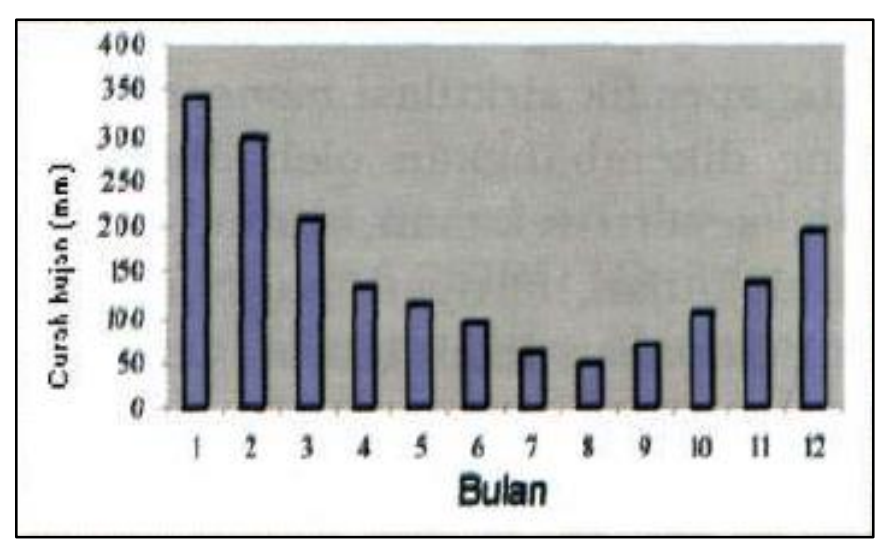

Gambar 2. Pola hujan monsunal di Jakarta (Sipayung et al., 2007)

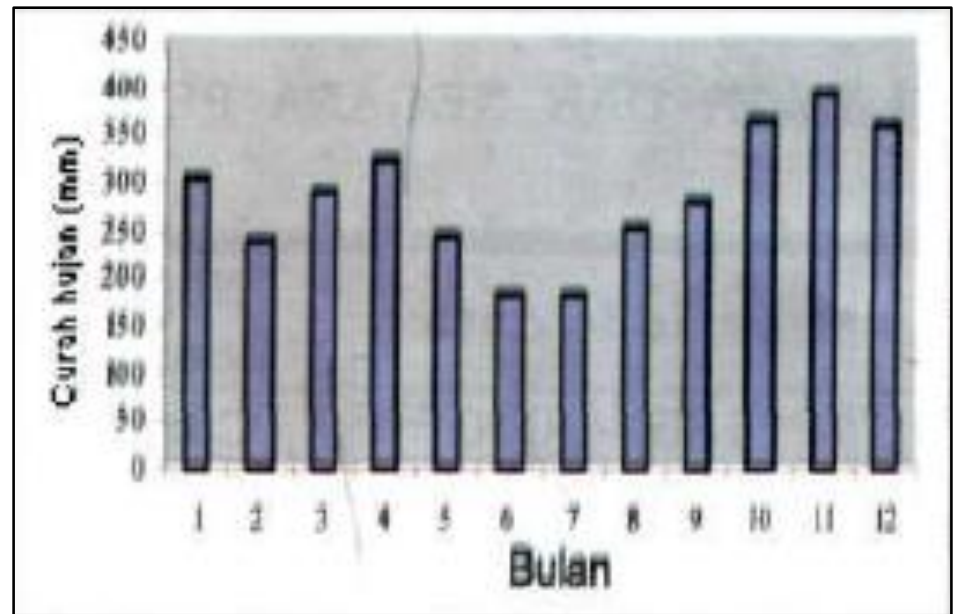

Gambar 3. Pola hujan equatorial di Padang (Sipayung et al., 2007)

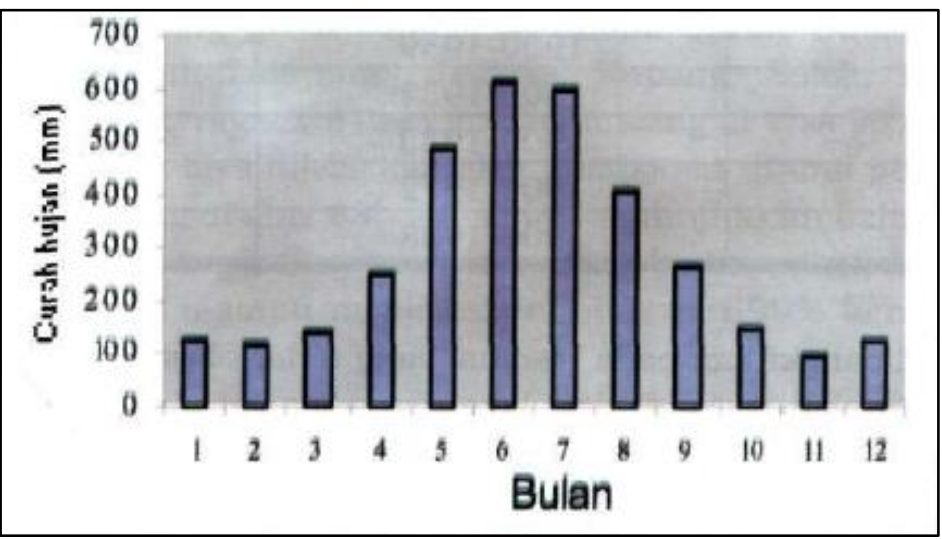

Gambar 4. Pola hujan lokal di Ambon (Sipayung et al., 2007)

\section{BAHAN DAN METODE}

\section{Tempat dan Waktu Penelitian}

Penelitian ini dilaksanakan di Gunungapi Sinabung Kabupaten Karo Provinsi Sumatera Utara dari bulan Juni 2017 sampai dengan bulan Januari 2018. Data yang digunakan adalah data sekunder curah hujan harian dari Badan Meteorologi Klimatologi dan Geofisika (BMKG) dari tahun 2000 sampai dengan tahun 2017 di Stasiun Klimatologi Sampali, Stasiun Geofisika Parapat dan Stasiun Geofisika Tuntungan, Provinsi Sumatera Utara.

\section{Alat dan Bahan}

Bahan yang dibutuhkan dalam penelitian ini adalah data curah hujan. Adapun alat-alat penelitian yang digunakan antara lain adalah seperangkat komputer yang dilengkapi dengan piranti lunak Microsoft Office XLStat dan alat tulis.

\section{Prosedur Penelitian}

Data curah hujan disajikan dalam tiga periode yaitu periode tahun 2000-2017, periode tahun 2000-2010 (periode sebelum letusan) dan periode 2011-2017 (setelah letusan). Pembagian periode waktu tersebut digunakan 
untuk mengetahui apakah terdapat perubahan pola hujan sebelum dan sesudah letusan Gunungapi Sinabung.

Salah satu tahapan penting dalam kajian perubahan iklim adalah pengujian homogenitas data runtun waktu unsur iklim (Sanusi, 2016). Tahapan ini merupakan bagian pra-pemrosesan data untuk mengurangi bias kesimpulan dari aspek noniklim (Nihayatin et al., 2013). Pengujian homogenitas yang digunakan dalam penelitian ini adalah Uji Rentang Buishand dengan persamaan:

$$
\mathrm{S}_{0} *=0 \quad \mathrm{~S}_{\mathrm{k}} *=\sum_{i=1}^{k} \mathrm{Yi}-\hat{\mathrm{Y}}
$$

Jika tidak ada perubahan signifikan dalam ratarata maka data akan homogen, dimana perbedaan data curah hujan Yi dan rata-rata $\hat{Y}$ akan berfluktuasi di sekitar nol (Buishand, 1982). Signifikansi perubahan rata-rata diuji dengan reschaled adjusted range $R$, yang merupakan selisih nilai maksimum dan minimum pembagian $\mathrm{Sk}^{*}$ dengan standar deviasi sampel.

$$
\begin{gathered}
R=\max _{0 \leq k \leq n} S_{k}^{* *}-\min _{0 \leq k \leq n} S_{k}^{* *} \\
\mathrm{Sk}^{* *}=\mathrm{Sk}^{*} / \mathrm{Dy}, \quad \mathrm{k}=0, \ldots, \mathrm{n} \\
\mathrm{Dy}^{2}=\sum_{i=1}^{n}(\mathrm{Yi}-\hat{\mathrm{Y}})^{2} / \mathrm{n}
\end{gathered}
$$

Setelah uji homogenitas dilakukan, data curah hujan harian diolah menjadi data curah hujan bulanan dan curah hujan tahunan. Data curah hujan selama periode penelitian digunakan untuk mengetahui pola hujan dan trend yang terjadi. Untuk mengetahui pola hujan di Gunungapi Sinabung, data curah hujan bulanan yang disajikan dalam diagram batang, sedangkan analisis trend menggunakan Uji Mann-Kendall.

Uji Mann-Kendall digunakan untuk melihat ada tidaknya kecenderungan pada suatu seri data dari data rentang waktu (Indarto et al., 2011). Uji Mann-Kendall sering digunakan untuk tes non-parametrik yang mempunyai kemampuan untuk mendeteksi kemiringan kecenderungan (trend), ukuran sampel, level signifikan, koefisien variasi dan tipe distribusi peluangnya (Subarna, 2014). Uji Mann-Kendall didasarkan pada S statistik yang diterangkan pada persamaan berikut:

$$
\begin{array}{lr}
(\mathrm{S}-1) / \sigma_{\mathrm{S}} & \text { jika } \mathrm{S}>0 \\
\mathrm{Z}=0 & \text { jika } \mathrm{S}=0 \\
(\mathrm{~S}+1) / \sigma_{\mathrm{S}} & \text { jika } \mathrm{S}<0 \\
\multicolumn{1}{c}{\sigma_{\mathrm{s}}{ }^{2}=} & \frac{\mathrm{n}(\mathrm{n}-1)(2 \mathrm{n}+5)}{18}
\end{array}
$$

Masing-masing pasangan nilai data yang diamati yi, yj (i>j) dari variabel acak diperiksa untuk menemukan apakah yi > yj atau yi < yj. Bila bilangan dari tipe pasangan sebelumnya berupa $\mathrm{P}$ dan bilangan tipe pasangan sesudahnya $\mathrm{M}$, maka $\mathrm{S}$ didefinisikan sebagai $\mathrm{S}=\mathrm{P}-\mathrm{M}$.

\section{HASIL DAN PEMBAHASAN}

\section{Uji Homogenitas}

Uji homogenitas dilakukan dengan menganalisis data setiap stasiun pada masing-masing bulan selama delapan belas tahun pada tahun 2000 sampai dengan 2017. Nilai statistik Hasil pengujian data runtun curah hujan menunjukkan bahwa data curah hujan tahun 2000-2017 pada tiga stasiun mempunyai nilai $\mathrm{R} / \sqrt{ } \mathrm{n}$ tidak lebih dari titik kritis yang ditetapkan pada Tabel 1 (Buishand, 1982). Data curah hujan yang digunakan memenuhi sifat homogen, disajikan pada Gambar 5.

Tabel 1. Nilai kritis untuk $\mathrm{R} \sqrt{ } \mathrm{n}$; nilai $\mathrm{n}=18$

\begin{tabular}{cccc}
\hline $\mathrm{n}$ & $90 \%$ & $95 \%$ & $99 \%$ \\
\hline 10 & 1.21 & 1.28 & 1.38 \\
20 & 1.34 & 1.43 & 1.60 \\
30 & 1.40 & 1,50 & 1,70 \\
40 & 1.42 & 1.53 & 1.74 \\
50 & 1.44 & 1.55 & 1.78 \\
100 & 1.50 & 1.62 & 1.86 \\
$\infty$ & 1.62 & 1.75 & 2.00 \\
\hline
\end{tabular}

\section{Analisis Pola Hujan}

BMKG membagi curah hujan bulanan menjadi empat kategori yaitu rendah $\left(0-100 \mathrm{~mm} \mathrm{bulan}^{-1}\right)$, sedang (100-300 mm bulan $\left.{ }^{-1}\right)$, tinggi (300-500 mm bulan $\left.{ }^{-1}\right)$ dan

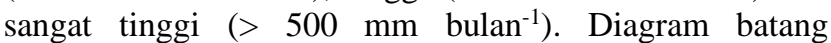
distribusi curah hujan bulanan rerata tiga stasiun menunjukkan bahwa pada periode tahun 2000-2017 puncak musim hujan terjadi pada bulan Mei sebesar 234 mm (menengah) dan pada bulan Oktober sebesar $312 \mathrm{~mm}$ (tinggi).

Pada periode sebelum letusan, puncak musim hujan terjadi pada bulan Mei (212 mm) dan Oktober (339 $\mathrm{mm})$. Untuk periode setelah letusan, puncak curah hujan terjadi pada bulan Mei (269 mm) dan September (276 $\mathrm{mm})$, disajikan pada Gambar 6. 


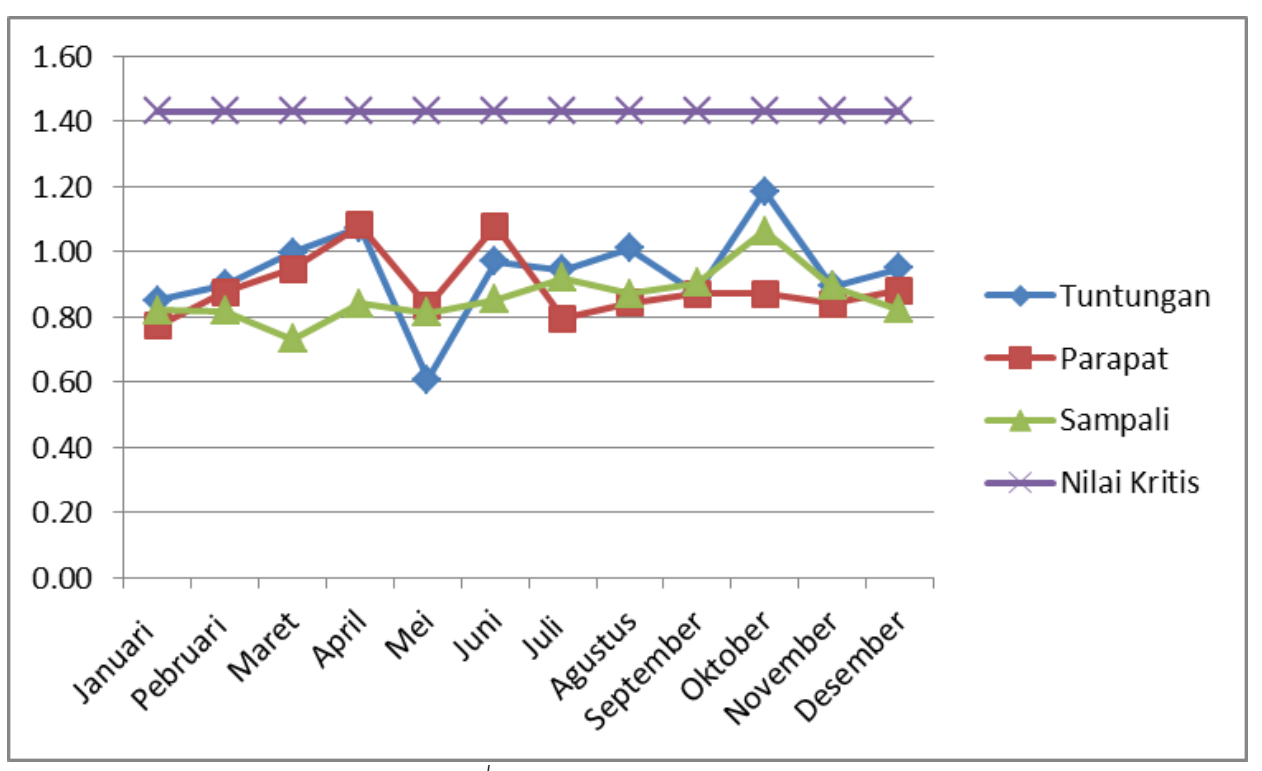

Gambar 5. Nilai $\mathrm{R} \sqrt{ } \mathrm{n}$ masing-masing stasiun dan nilai kritis

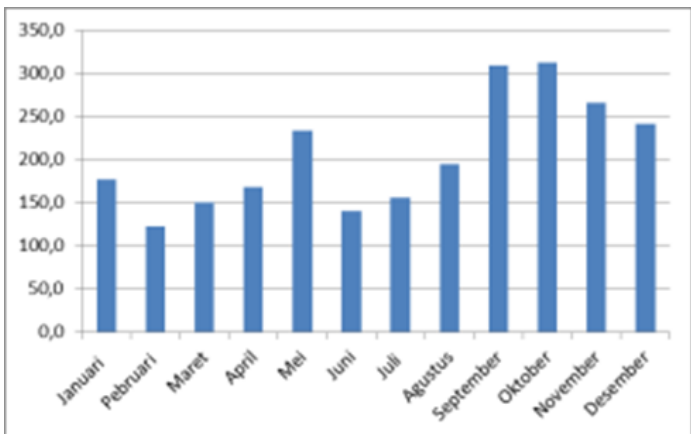

(a)

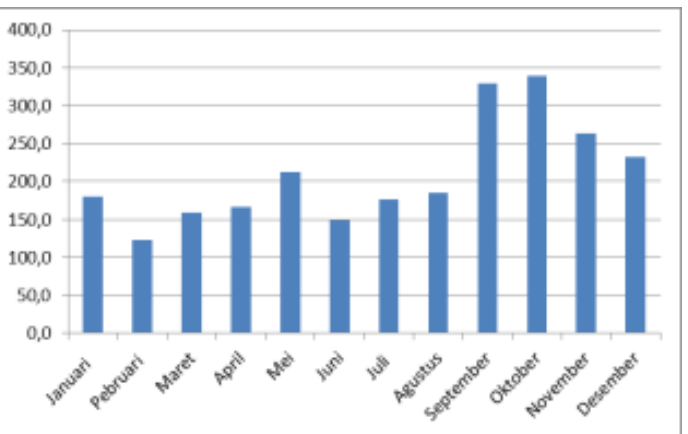

(b)

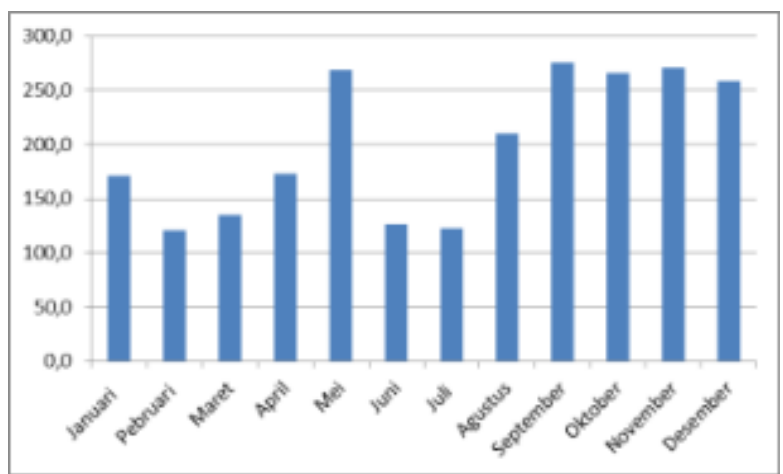

(c)

Gambar 6. Distribusi curah hujan bulanan rerata periode: (a) 2000-2017, (b) 2000-2010, dan (c) 2011-2017

Pada periode sebelum letusan, setelah bulan Oktober curah hujan mengalami penurunan yang signifikan dari $339 \mathrm{~mm}$ menjadi $263 \mathrm{~mm}$ pada November dan $233 \mathrm{~mm}$ pada bulan Desember. Namun setelah terjadi letusan, curah hujan pada bulan September sampai dengan Desember hanya mengalami sedikit penurunan dari 276 $\mathrm{mm}$ menjadi $266 \mathrm{~mm}$, naik lagi menjadi $270 \mathrm{~mm}$ kemudian turun menjadi $258 \mathrm{~mm}$. Dari ketiga periode tahun tersebut, semuanya menunjukkan bahwa pola hujan di Gunungapi Sinabung merupakan pola hujan equatorial.

\section{Analisis Trend Curah Hujan}

Trend curah hujan bulanan rerata dalam tiga periode disajikan pada Tabel 2. Curah hujan kumulatif bulanan pada bulan Mei dan bulan November mempunyai 
trend naik pada semua periode. Pada periode setelah letusan, kecenderungan turun hanya pada bulan Maret, April dan Desember, sedangkan pada bulan lainnya mengalami kecenderungan naik.

Tabel 2. Trend curah hujan bulanan kumulatif di Gunungapi Sinabung

\begin{tabular}{lccc}
\hline \multirow{2}{*}{ Bulan } & \multicolumn{3}{c}{ Periode Tahun } \\
\cline { 2 - 4 } Januari & turun & turun & naik \\
Februari & turun & turun & naik \\
Maret & turun & turun & turun \\
April & turun & naik & turun \\
Mei & naik & naik & naik \\
Juni & turun & turun & naik \\
Juli & turun & naik & naik \\
Agustus & naik & turun & naik \\
September & turun & turun & naik \\
Oktober & turun & turun & naik \\
November & naik & naik & naik \\
Desember & naik & naik & turun \\
\hline \multicolumn{4}{c}{ SIMPULAN }
\end{tabular}

Pola hujan di Gunungapi Sinabung merupakan pola hujan equatorial, hal tersebut ditandai dengan adanya dua puncak musim hujan selama satu tahun. Puncak musim hujan pada bulan Mei mempunyai kecenderungan naik, hal ini harus diwaspadai karena dapat menyebabkan aliran lahar. Masyarakat tetap harus meningkatkan kesiapsiagaannya pada bulan dengan curah hujan menengah-tinggi pada September, Oktober, November dan Desember.

\section{DAFTAR PUSTAKA}

Aldrian, E. and R.D. Susanto. 2003. Identification of three dominant rainfall regions within Indonesia and their relationship to sea surface temperature. International Journal of Climatology, 23(12): 1435-1452.

[BPS] Badan Pusat Statistik Kabupaten Karo. 2015. Karo dalam Angka. Karo (ID): BPS Kabupaten Karo.

[BG] Badan Geologi. Gunung Sinabung. https://magma.vsi.esdm.go.id/ (diakses tanggal 30 Desember 2017).

Buishand, T.A. 1982. Some methods for testing the homogeneity of rainfall records. Journal of Hidrology, 58(1-2): 11-27.

Hermawan, E. 2010. Pengelompokkan pola curah hujan yang terjadi di beberapa kawasan pulau Sumatera berbasis hasil analisis teknik spektral. Jurnal
Meteorologi dan Geofisika, 11(2): 75 - 85.

Hidayat, F. dan I. Rudiarto. 2013. Pemodelan resiko banjir lahar hujan pada alur kali putih Kabupaten Magelang. Jurnal Teknik PWK, 2(4):895-904.

Indarto, B. Susanto dan E.M. Diniardi. 2011. Analisis kecenderungan data hujan di Jawa Timur menggunakan metode Mann-Kendal dan Rank-Sum Test. Jurnal Keteknikan Pertanian, 25(1):19-28.

Nihayatin, L.Z. dan Sutikno. 2013. Perbandingan uji homogenitas runtun data curah hujan sebagai prapemrosesan kajian perubahan iklim. Jurnal Sains dan Seni Pomits, 2(2):255-259.

Pierson, T.C., N. Wood and C.L. Driedger. 2014. Reducing risk from lahar hazards: concepts, case studies, and roles for scientists. Journal of Applied Volcanology, 3(16): 1-25.

Saragih, J., D. Chalil dan S. Khadijah. 2015. Analisis dampak erupsi gunungapi sinabung terhadap pendapatan petani kubis di Kecamatan Simpang Empat. Journal on Social Economic of Agriculture and Agribusiness, 4(5): 1-13.

Schilling, S.P. 2014. Laharz_py-GIS Tools for Automated Mapping of Lahar Inundation Hazard Zones. US Geological Survey, Virginia.

Sipayung, S.B., Sutikno, L.Q. Avia dan B.D. Dasanto. 2007. Analisis pola curah hujan Indonesia berbasis luaran Model Sirkulasi Global (GCM). Jurnal Sains Dirgantara, (4)2:145-154.

Sanusi, W. 2016. Analisis homogenitas data curah hujan tahunan Kota Makassar. Jurnal Scientific Pinisi, 2(2):137-142

Subarna, D. 2014. Uji Kecenderungan unsur-unsur iklim di cekungan Bandung dengan Metode Mann-Kendall. Berita Dirgantara, 15(1):1-6.

Yulianto, F., Suwarsono and P. Sofan. 2016. The utilization of remotely sensed data to analyze the estimated volume of pyroclastic deposits and morphological changes caused by the 2010-2015 eruption of Sinabung Volcano, North Sumatra, Indonesia. Pure and Applied Geophysics, 173.

Vallance, J.W., S.P. Schilling, G. Devoli and M.M. Howell. 2014. Lahar Hazards at Concepcion Volcano, Nicaragua. U.S. Geological Survey, Vancouver WA, US. 